\title{
Acute Ischemic and Hemorrhagic Stroke and COVID-19: Case Series
}

\author{
Poya Fatehi ${ }^{1}$ - Negin Hesam-Shariati ${ }^{2}$. Morteza Abouzaripour ${ }^{3}$. Fardin Fathi ${ }^{4}$. \\ Mohammad Bakhtiar Hesam Shariati ${ }^{3}$ (i)
}

Accepted: 28 September 2020 / Published online: 1 October 2020

(C) Springer Nature Switzerland AG 2020

\begin{abstract}
The coronavirus COVID-19 pandemic is the defining global health crisis of our time and the greatest challenge we have faced since the World Wars; it can attack several systems in the body and has high complications and mortality. COVID19 can cause venous and arterial thromboembolism due to immobility, high inflammation, extensive intravascular blood coagulation, and hypoxia. In this study, we report 5 cases of adults with COVID-19, hospitalized in Tohid Hospital, Sanandaj, Iran. Three patients were male and two were female. The youngest patient was 20 years old and the oldest was 55 years old. All patients had at least one family member with coronavirus. Fever, chills, muscular pain, cough, and tachypnea were present in all patients. Red blood cell (RBC) was observed in all patients at a low level. Computed tomography (CT) scans of all patients showed abnormal findings in different areas of the brain. These cases indicate that COVID-19 may damage blood vessels in the brain and lead to stroke.
\end{abstract}

Keywords Coronavirus $\cdot$ Ischemic $\cdot$ COVID-19 $\cdot$ Stroke $\cdot$ Computed tomography

\section{Introduction}

COVID-19 (coronavirus) is a viral respiratory disease, which has infected many people around the world in the past 6 months. The World Health Organization (WHO) declared COVID-19 as a global health emergency in January 2020 [1]. Dry cough and fever are two of the most common symptoms of this disease, which can cause complications such as chest pain, acute respiratory distress syndrome (ARDS), and vascular insufficiency [2]. Factors such as old age, hypertension, diabetes, neutrophilia, lymphocytopenia, high inflammatory indicators, and blood coagulation disorders are the key agents

This article is part of the Topical Collection on Covid-19

Mohammad Bakhtiar Hesam Shariati

b.hesamshariati@gmail.com; m.hesamshariati@muk.ac.ir

1 Department of Radiology, Tohid Hospital, Kurdistan University of Medical Sciences, Sanandaj, Iran

2 School of Medical Sciences, Faculty of Medicine, University of New South Wales, Sydney, Australia

3 Department of Anatomical Sciences, Faculty of Medicine, Kurdistan University of Medical Sciences, Sanandaj, Iran

4 Cellular and Molecular Research Center, Research Institute for Health Development, Kurdistan University of Medical Sciences, Sanandaj, Iran in causing death and respiratory distress in patients with COVID-19 [1].

There is ample evidence that the COVID-19 effects are not always limited to the respiratory system but can also impair the cardiovascular, gastrointestinal, urinary, reproductive, and nervous systems $[3,4]$. Symptoms of coronavirus affecting the nervous system can be classified into three groups: (1) symptoms of central nervous system that include headache, vertigo, acute cerebrovascular disease, and epilepsy; (2) symptoms of peripheral nervous system that include loss of appetite and loss of sense of smell and taste; and (3) damage to skeletal muscles $[5,6]$. In addition, patients are at high risk of thrombosis due to their over-coagulation status, blood stasis, and endothelial damage [7]. Furthermore, recent studies have shown that patients with COVID-19 usually have high concentrations of cytokines including IL2, IL7, IL10, GCSF, IP10, MCP1, MIP1A, and TNF $\alpha[2,8]$. Stroke is currently one of the most common health problems in developed countries and was the second leading cause of death worldwide according to the WHO latest report [9]. Recently, the importance of this issue in developing countries has become more prominent [10]. However, no cases of acute vascular disease have been reported so far. In this article, we report several cases of patients with coronavirus with brain disorders who have been admitted to Tohid Hospital in Sanandaj, Iran. Written informed consent was obtained from a legally 
authorized representative(s) for anonymized patient information to be published in this article which was approved by the Research Center of Kurdistan University of Medical Sciences.

\section{Case Presentations}

\section{Case 1}

A 35-year-old man was infected with the coronavirus after attending a wedding. Symptoms such as fever, chills, muscular pain, weakness, cough, tachycardia, and acute respiratory syndrome have been reported. He was hospitalized in the Tohid Hospital, Sanandaj, Iran. He had no history of underlying diseases. Two of his brothers were also infected with the coronavirus. All of the patient's clinical findings, including cardiovascular and abdominal examinations, were normal. The amount of oxygen measured in the blood, when referred to the Corona Emergency Department, was reported to be $67 \%$. There was no evidence of arrhythmia in the patient. The patient had a history of smoking for 5 years. All laboratory findings of this patient are presented in Table 1. Coronavirus test results were positive. Computed tomography (CT) scans of his chest were performed to confirm the presence of coronavirus, and the images showed that the patient had coronavirus (Fig. 1). In the next step, due to frequent headaches and decreased consciousness, the patient underwent a brain CT scan by the order of a neurologist who observed the initial images and examinations (Fig. 2) of the hypodense areas in the left parietal area. Ischemic stroke was confirmed by a radiologist from the CT scan. Supportive care, antibiotics, and other treatments were used to treat the patient. After 20 days, the patient's general condition improved, and his respiratory and nervous symptoms gradually subsided.

\section{Case 2}

A 52-year-old woman was examined at the Corona Emergency Department of Tohid Hospital in Sanandaj, Iran, with fever, cough, headache, myalgia, and photophobia. Although she denied any close contact with others in the previous month, the information from her family confirmed that she had attended two friendly parties over the past month. During hospitalization in Tohid Hospital emergency department, the patient's physical examination was reported including body temperature of $38.4{ }^{\circ} \mathrm{C}$, blood pressure of $73.86 \mathrm{mmHg}$, pulse rate of 90 beats/min, respiration rate of 22 breaths $/ \mathrm{min}$, and blood oxygen

Table 1 The results of laboratory findings

\begin{tabular}{|c|c|c|c|c|c|c|c|c|}
\hline & Test name & Unit & Reference range & Case 1 & Case 2 & Case 3 & Case 4 & Case 5 \\
\hline 1 & BUN & $\mathrm{mg} / \mathrm{dl}$ & $7-16.8$ & 18 & $66 \mathrm{Hi}$ & $21 \mathrm{Hi}$ & $31 \mathrm{Hi}$ & $110 \mathrm{Hi}$ \\
\hline 2 & $\mathrm{Ca}$ & $\mathrm{mg} / \mathrm{dl}$ & $8.6-10.3$ & & 9 & & & 6.8 low \\
\hline 3 & $\mathrm{p}$ & $\mathrm{mg} / \mathrm{dl}$ & $2.7-4.5$ & & $5.1 \mathrm{Hi}$ & & & $4.7 \mathrm{Hi}$ \\
\hline 4 & $\mathrm{Na}$ (ser) & $\mathrm{mEq} / \mathrm{L}$ & $138-145$ & 144 & & $150 \mathrm{Hi}$ & 143 & 138 \\
\hline 5 & $\mathrm{~K}(\mathrm{ser})$ & $\mathrm{mEq} / \mathrm{L}$ & $3.6-5.9$ & 3.8 & 5 & 2.4 low & 4 & 4.1 \\
\hline 6 & $\mathrm{MCH}$ & pg & $27.5-33.2$ & 27.6 & 30.5 & 23.1 & 32.3 & 31 \\
\hline 7 & $\mathrm{MCHC}$ & $\mathrm{g} / \mathrm{dL}$ & $30.0-38.0$ & 33.2 & 31.8 & 29.9 & 33.2 & 36 \\
\hline 8 & Plt & $\times 1000 / \mu \mathrm{L}$ & $140-440$ & 161 & & 150 & 245 & \\
\hline 9 & $\mathrm{Cr}$ & $\mathrm{mg} / \mathrm{dl}$ & $\begin{array}{l}\text { Female: } 0.6-1.3 \mathrm{mg} / \mathrm{dl} \\
\text { Male: } 0.8-1.3 \mathrm{mg} / \mathrm{dl}\end{array}$ & 1.16 & $8.3 \mathrm{Hi}$ & 1.1 & 1.1 & $7.9 \mathrm{Hi}$ \\
\hline 10 & SGOT(AST) & $\mathrm{IU} / \mathrm{L}$ & $\begin{array}{l}\text { Female up to } 31 \\
\text { Male: }<40\end{array}$ & & 14 & 16 & 15 & \\
\hline 11 & SGPT(ALT) & $\mathrm{IU} / \mathrm{L}$ & $\begin{array}{l}\text { Female: }<31 \\
\text { Male: }<45\end{array}$ & & 11 & 13 & 10 & \\
\hline 12 & WBC & $\times 1000 / \mu \mathrm{L}$ & $4.4-11$ & 7.1 & 7.0 & 9.6 & 10.1 & $16.9 \mathrm{Hi}$ \\
\hline 13 & $\mathrm{RBC}$ & $\times 1,000,000 / \mu \mathrm{L}$ & $\begin{array}{l}\text { Female: } 4.5-5.1 \\
\text { Male: } 4.5-6.5\end{array}$ & $\begin{array}{l}4.09 \\
\text { Low }\end{array}$ & 3.80 low & 3.55 low & 4.27 low & 4.06 low \\
\hline 14 & $\mathrm{Hb}$ & $\mathrm{g} / \mathrm{dl}$ & $\begin{array}{l}\text { Female: } 12.3-15.3 \\
\text { Male: } 14-17\end{array}$ & 13.2 & 11.6 low & 6.2 low & 13.2 low & 15.4 \\
\hline 15 & Hct & $\%$ & $\begin{array}{l}\text { Female: } 36-44.5 \\
\text { Male: } 41.5-50.4\end{array}$ & 39.8 & 36.5 & 27.4 Low & 41.6 & 42.8 \\
\hline 16 & $\mathrm{MCV}$ & $\mathrm{fl}$ & $80-96$ & & 96.1 & 77.7 & $97 / 4$ & 86.3 \\
\hline 17 & FBS & $\mathrm{mg} / \mathrm{dl}$ & $70-115$ & & 85 & & $130 \mathrm{Hi}$ & \\
\hline 18 & ALK.P & IU/L & Male: 0-270 & & $400 \mathrm{Hi}$ & & $309 \mathrm{Hi}$ & \\
\hline 19 & CRP & $\mathrm{mg} / \mathrm{L}$ & $0-6$ & & & & 8 & \\
\hline 20 & ESR & $\mathrm{mm}$ & $5-12$ & & & & $28 \mathrm{Hi}$ & \\
\hline
\end{tabular}


Fig. 1 Axial without contrastenhanced chest computed tomography $(\mathrm{CT})$ image showing a coronavirus disease (COVID-19) infection

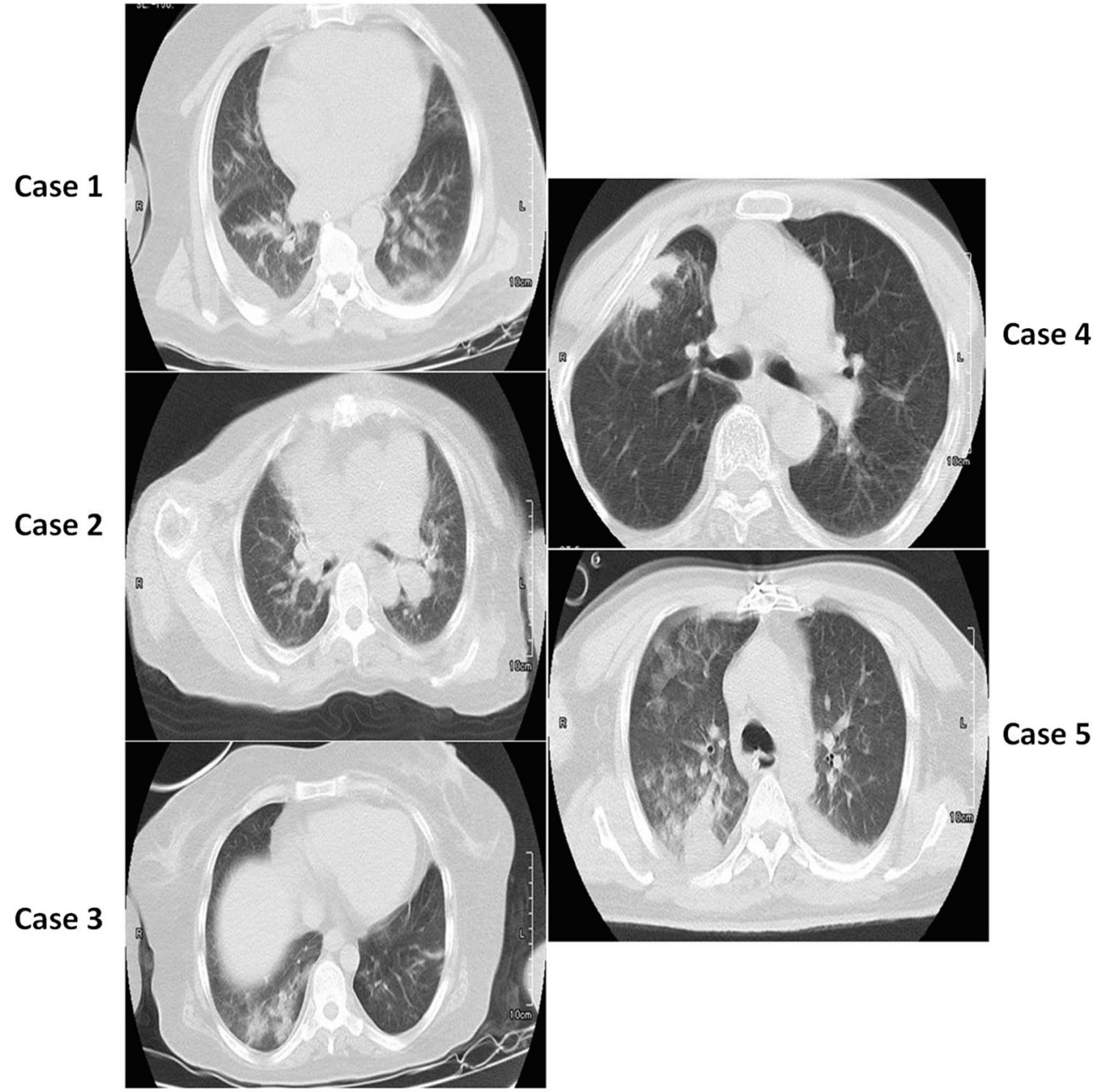

saturation of $73 \%$ in $51 / \mathrm{min}$ of oxygen. Mild hypoxemia was diagnosed due to low oxygen levels in the patient's blood. The most common blood and electrolyte tests were reported to be normal. Testing for other viral diseases, including influenza A and $\mathrm{B}$, was negative. Other laboratory findings were in accordance with Table 1. Preliminary results of the coronavirus test were negative, but in the second test, she was diagnosed with coronavirus, and the CT images of lungs were a definite indication of the virus (Fig. 1). Due to the persistent headache during the treatment period, a brain CT scan was taken, the radiologist distinguished the hypodense lesions in the parietal lobe on the right, and an ischemic stroke was confirmed (Fig. 2). Supportive care, antibiotics, and antiviral treatments were performed. After a month, the general condition of the patient improved and the viral and neurological symptoms were gradually ameliorated.

\section{Case 3}

A 50-year-old woman was admitted to the ICU of Tohid Hospital, Sanandaj, Iran, with symptoms of fever, tachypnea, respiratory problems, severe headache, frequent vomiting, and decreased consciousness. The initial physical and clinical examinations were normal, and the patient's history showed no underlying disease. He was not taking any special medications at the time and had no history of alcohol or tobacco use. Her blood pressure was $238 / 112 \mathrm{mmHg}$ with a regular pulse rate of 116 beats/min, a respiratory rate of 21 cycles/min, and a temperature of $38.1^{\circ} \mathrm{C}$. While there was no evidence of arrhythmia, the patient had mild hypoxemia with oxygen levels of $85-90 \%$. The patient's important laboratory findings are listed in Table 1. This patient had normal chest radiographs despite positive reverse transcription-polymerase chain reaction (RT-PCR) test. But high-resolution CT scan of the chest revealed evidence of the coronavirus (Fig. 1). She was treated in the intensive care unit and was able to breathe using a ventilator a few hours after being admitted to the ICU. Due to decreased level of consciousness, according to the neurologist order, a brain CT scan was taken. The non-contrast CT scan showed hyperdense areas in the left parietal lobe, which caused bleeding in the brain tissue (Fig. 2). However, the brain images did not indicate any brain shift or hydrocephalus in the brain tissue. Patient underwent supportive, antibiotic, and 
Fig. 2 Axial CT scan without injection brain images. Cranial CT scan imaging showed the areas of the hypodermis in the left parietal region of the brain (case 1). Cranial CT scan imaging showed the areas of the hypodermis in the right parietal region of the brain (case 2). Cranial CT scan imaging showed the areas of the hyper dense in the left parietal region of the brain (case 3). Cranial CT scan imaging showed the areas of the hypodermis in the cerebellum region of the brain (case 4). Cranial CT scan imaging showed the areas of the hypodermis in the left parietal region of the brain (case 5)
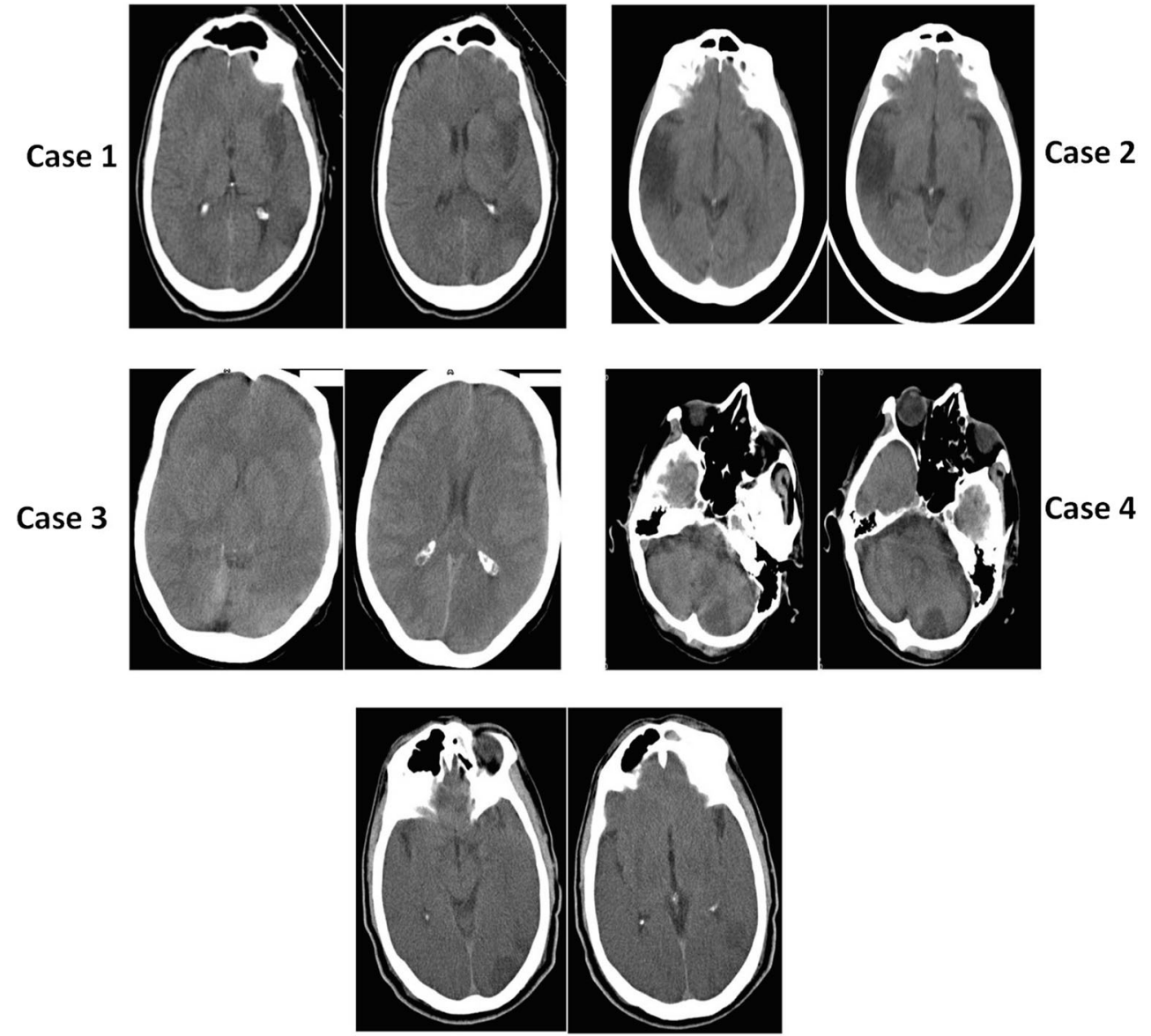

Case 5 pharmacological care to control intracerebral hemorrhage and to treat for coronavirus. Unfortunately, the patient died 2 days after being admitted to the hospital's intensive care unit.

\section{Case 4}

An 18-year-old young boy patient was admitted to the emergency department of Tohid Hospital, Sanandaj, Iran, with symptoms of quadriparesis. The patient's nervous manifestations began 5 days before hospitalization. He experienced bilateral facial paresis accompanied by progressive weakness, but there was no urinary and fecal incontinence. There were signs of an imbalance in him. His first symptoms were cough and shortness of breath 1 week before hospitalization when he was referred to an allergy specialist and was diagnosed with coronavirus disease after testing for RT-PCR and a confirmative CT scan of the chest. At the time, the patient was treated with hydroxychloroquine and azithromycin. There was no evidence of underlying disease in the patient's history, and physical examination showed that the patient was afebrile with blood pressure of $110 / 80 \mathrm{~mm} / \mathrm{hg}$, respiratory rate of $18 / \mathrm{min}$, oxygen saturation of $81 \%$ on room air, and heart rate of 68 beats $/ \mathrm{min}$. At the time of hospitalization, the patient was conscious but had respiratory distress. Lung CT scan revealed diffused consolidations and ground-glass opacities in both lungs and bilateral pleural effusion (Fig. 1). The important laboratory results of the patient are shown in Table 1 . On day 3 of hospitalization, brain imaging was performed using CT. The non-contrast CT scan showed hypodense areas in the cerebellum, indicating an ischemic stroke (Fig. 2). However, the brain images did not indicate any brain shift or hydrocephalus in the brain tissue.

\section{Case 5}

A 55-year-old male was admitted to Tohid Hospital in Sanandaj, Iran, with abdominal pain, nausea, and vomiting. He admitted that he had not complied with any of the health protocols against coronavirus. After 3 days, the laboratory reported positive result for the patient's RT-PCR test. Additionally, CT scans showed the effects of coronavirus in the patient's lungs (Fig. 1). So, she was a confirmed case of 
coronavirus according to the diagnostic protocols. In the hospitalization period, the physical examinations indicated a body temperature of $38.9^{\circ} \mathrm{C}$, blood pressure of $94 / 74 \mathrm{mmHg}$, pulse rate of 89 beats $/ \mathrm{min}$, breathing rate of 35 breaths $/ \mathrm{min}$, and the blood oxygen saturation of $90 \%$ at $5 \mathrm{l} / \mathrm{min}$ of oxygen. The routine blood tests, kidney function, electrolyte, and serum procalcitonin were normal. The extra laboratory results are presented in Table 1. The patient's doctor ordered an ultrasound of the abdomen due to recurring abdominal pain and vomiting. The ultrasound showed that all abdominal and pelvic organs were normal except for both kidneys. Due to decreased level of consciousness, according to the neurologist order, a brain $\mathrm{CT}$ scan was taken. CT scan without contrast shows excessive areas in the lobe of the left body, indicating an ischemic stroke (Fig. 2).

\section{Discussion}

Some patients with coronavirus, specifically those with older age and chronic medical situations such as diabetes, hypertension, cancer, and pulmonary asthma, may be at risk for acute respiratory distress syndrome and organ dysfunction $[10,11]$. Evidence from previous studies have indicated that patients with severe coronavirus disease might experience respiratory failure with an urgent need for artificial respiration, and other organ dysfunction [7]. Pathophysiological studies have also shown that patients with coronavirus are prone to dehydration due to fever, diarrhea, hypotension, and secondary infections, which can lead to venous thrombosis [12]. Risk classification for thrombotic and hemorrhagic strokes disease is of crucial importance for prediction of coronavirus.

In addition, severe acute respiratory syndrome coronavirus 2 (SARS-CoV-2) have been reported to attack the heart and some major arteries that lead to a damage to the nervous system $[6,13]$. According to studies, coronavirus can play a decisive role in causing strokes and vascular complications in general [14]. Another study by Rothstein et al. showed that most patients with ischemic stroke have common vascular risk agents and stroke mechanisms [15].

Numerous studies have shown that angiotensin-converting enzyme 2 (ACE2) is highly expressed in human tissues such as vascular endothelial cells, heart, gastrointestinal tract, and urinary system $[16,17]$. Furthermore, Tsaytler et al. showed that ACE2 is a major target in human SARS-CoV-2 infections. After the coronavirus infection, the level of ACE2 decreases or may even disappear completely [18]. Therefore, they reported that all tissues and organs in which the ACE2 is expressed may be in the conflict zone between SARS-CoV2 and immune cells, eventually leading to organ failure and death $[18,19]$.

Thus, to reduce the side effects and death rate of coronavirus, it is necessary to assess the risks of arterial and venous thrombosis, and lesions in the central nervous system. As it is known, cerebral hemorrhage refers to spontaneous hemorrhage in cerebral parenchyma without any head injury [20]. The most common causes of cerebral hemorrhage include high blood pressure, hardening of the cerebral arteries, intravascular and vascular anomaly, and cerebral amyloid [21]. Rupture of a small artery caused by high blood pressure can lead to death shortly due to effects of bleeding on the body's main activities, such as breathing and heart pumping. Acute cerebrovascular diseases are one of the most common diseases in middle-aged and elderly people, and with its wide range of effects, it can lead to high mortality and disability [22]. Studies have also shown that in addition to a pandemic, the coronavirus will cause a widespread stroke epidemic [23]. Therefore, due to these symptoms, care measures are necessary to prevent a stroke epidemic in people with COVID-19 disease [24].

Most patients with coronavirus can be treated, but many will not survive due to the destructive effects of the virus on vital organs. The main cause of death in patients with coronavirus is respiratory distress, followed by vital organ dysfunction, cardiovascular failure, and bleeding. Studies have shown that the coronavirus mainly involves the respiratory, cardiovascular, digestive, and urinary systems. In many cases, liver and kidney functions are disrupted. A coronavirus study by Zhang B et al. concluded that the SARS-CoV-2, in addition to directly attacking the tissues and organs of the body, triggers a cytokine storm by stimulating the immune system [25]. They reported that many patients with severe coronavirus were exposed to the cytokine storm, which is considered a reaction of the body's immune system to the virus [25]. In this reaction, a large number of anti-inflammatory agents such as interleukin1 , interleukin-6, and tumor necrosis factor are released, and excessive activation of immune cells is a non-specific cause [26]. Therefore, according to these results, it is recommended that medical team members consider two goals in the treatment process of patients with coronavirus: first, the protection of organs and functioning of the body's systems against invasion and damage and, second, strengthening the immune system to control the formation of cytokine storms.

\section{Conclusion}

In general, coronavirus is highly contagious, and although accurate information is not yet available, early detection can help treat the disease. Coronavirus can damage the vascular system and cause bleeding; this damage to the nervous system can be accompanied by dysfunction of another system in the body. Thus, early treatment can be very beneficial for this prognostic disease. In addition, it has been shown that the virus can weaken the immune system with secondary pathogen infections in the body, so it is necessary to strengthen the immune system. 
Acknowledgments The authors thank all the teaching and medical staff of Kurdistan University of Medical Sciences for their effort in eradicating this virus.

Author Contributions MBHS supervised the study and drafted the manuscript; PF collected the clinical data; MA and FF analyzed the data and images; and NHS reviewed the manuscript.

Compliance with Ethical Standards Written informed consent was obtained from a legally authorized representative(s) for anonymized patient information to be published in this article. This research has been confirmed by the Research Center of Kurdistan University of Medical Sciences with the file number IR.MUK.REC.1399.060.

Conflict of Interest All authors declare that they have no conflict of interest.

\section{References}

1. Poggiali E, et al. Deep vein thrombosis and pulmonary embolism: two complications of COVID-19 pneumonia? Eur J Case Rep Intern Med. 2020;7(5).

2. Huang $\mathrm{C}$, Wang Y, Li X, Ren L, Zhao J, Hu Y, et al. Clinical features of patients infected with 2019 novel coronavirus in Wuhan, China. Lancet. 2020;395(10223):497-506.

3. Liu Y, Liu Z, Xiang J, Wang Y, Song B, Gu X, et al. Clinical course and risk factors for mortality of adult inpatients with COVID-19 in Wuhan, China: a retrospective cohort study. Lancet. 2020;395: 1054-62.

4. Li B, Yang J, Zhao F, Zhi L, Wang X, Liu L, et al. Prevalence and impact of cardiovascular metabolic diseases on COVID-19 in China. Clin Res Cardiol. 2020;109(5):531-8.

5. Li YC, Bai WZ, Hashikawa T. The neuroinvasive potential of SARS-CoV2 may play a role in the respiratory failure of COVID19 patients. J Med Virol. 2020;92(6):552-5.

6. Mao, L., et al., Neurological manifestations of hospitalized patients with COVID-19 in Wuhan, China: a retrospective case series study. 2020.

7. Zhou B, et al. Venous thrombosis and arteriosclerosis obliterans of lower extremities in a very severe patient with 2019 novel coronavirus disease: a case report. J Thromb Thrombolysis. 2020:1-4.

8. China, N., New coronavirus pneumonia prevention and control program. 2020.

9. Organization, W.H. Global action plan on physical activity 20182030: more active people for a healthier world: World Health Organization; 2019.

10. Sagui E, M'Baye PS, Dubecq C, Ba Fall K, Niang A, Gning S, et al. Ischemic and hemorrhagic strokes in Dakar, Senegal: a hospitalbased study. Stroke. 2005;36(9):1844-7.
11. Bai Y, Yao L, Wei T, Tian F, Jin DY, Chen L, et al. Presumed asymptomatic carrier transmission of COVID-19. Jama. 2020;323(14):1406-7.

12. Zhai Z, Li C, Chen Y, Gerotziafas G, Zhang Z, Wan J, et al. Prevention and treatment of venous thromboembolism associated with coronavirus disease 2019 infection: a consensus statement before guidelines. Thromb Haemost. 2020;120:937-48.

13. Butowt R, Bilinska K. SARS-CoV-2: olfaction, brain infection, and the urgent need for clinical samples allowing earlier virus detection. ACS Chem Neurosci. 2020;11(9):1200-3.

14. Saggese CE, del Bianco C, di Ruzza MR, Magarelli M, Gandini R, Plocco M. COVID-19 and stroke: casual or causal role? Cerebrovasc Dis. 2020;49(3):341-4.

15. Rothstein A, Oldridge O, Schwennesen H, Do D, Cucchiara BL. Acute cerebrovascular events in hospitalized COVID-19 patients. Stroke. 2020;51(9):e219-22.

16. Alenina N, Bader M. ACE2 in brain physiology and pathophysiology: evidence from transgenic animal models. Neurochem Res. 2019;44(6):1323-9.

17. Wu X, Zhu B, Zou S, Shi J. The association between ACE2 gene polymorphism and the stroke recurrence in Chinese population. J Stroke Cerebrovasc Dis. 2018;27(10):2770-80.

18. Tsaytler P, Harding HP, Ron D, Bertolotti A. Selective inhibition of a regulatory subunit of protein phosphatase 1 restores proteostasis. Science. 2011;332(6025):91-4.

19. Bao Y, et al. Clinical features of COVID-19 in a young man with massive cerebral hemorrhage - case report. Sn Compr Clin Med. 2020:1.

20. Aguilar MI, Freeman WD. Spontaneous intracerebral hemorrhage. in Seminars in neurology: (c) Thieme Medical Publishers; 2010.

21. Tanaka H, Ueda Y, Hayashi M, Date C, Baba T, Yamashita H, et al. Risk factors for cerebral hemorrhage and cerebral infarction in a Japanese rural community. Stroke. 1982;13(1):62-73.

22. Toyoda K, Koga M, Yamamoto H, Foster L, Palesch YY, Wang Y, et al. Clinical outcomes depending on acute blood pressure after cerebral hemorrhage. Ann Neurol. 2019;85(1):105-13.

23. Tsivgoulis $\mathrm{G}$, et al. Ischemic stroke epidemiology during the COVID-19 pandemic: navigating uncharted waters with changing tides. Am Heart Assoc. 2020.

24. Dafer RM, Osteraas ND, Biller J. Acute stroke care in the coronavirus disease 2019 pandemic: Elsevier; 2020.

25. Zhang B, et al. Clinical characteristics of 82 death cases with COVID-19: MedRxiv; 2020.

26. Liu B, et al. Can we use interleukin-6 (IL-6) blockade for coronavirus disease 2019 (COVID-19)-induced cytokine release syndrome (CRS)? J Autoimmun. 2020:102452.

Publisher's Note Springer Nature remains neutral with regard to jurisdictional claims in published maps and institutional affiliations. 